RESEARCH PAPER

\title{
Tobacco-related disease mortality among men who switched from cigarettes to spit tobacco
}

\author{
S Jane Henley, Cari J Connell, Patricia Richter, Corinne Husten, Terry Pechacek, Eugenia E Calle, \\ Michael J Thun
}

Tobacco Control 2007;16:22-28. doi: 10.1136/tc.2006.018069

See end of article for authors' affiliations

Correspondence to:

$M$ Thun, Epidemiology and Surveillance Research, American Cancer Society, 1599 Clifton Road, NE, Atlanta, GA 30329, USA michael.thun@cancer.org

Received 31 July 2006 Accepted 17 August 2006
Background: Although several epidemiological studies have examined the mortality among users of spit tobacco, none have compared mortality of former cigarette smokers who substitute spit tobacco for cigarette smoking ("switchers") and smokers who quit using tobacco entirely.

Methods: A cohort of 116395 men were identified as switchers $(n=4443$ ) or cigarette smokers who quit using tobacco entirely ( $n=111$ 952) when enrolled in the ongoing US American Cancer Society Cancer Prevention Study II. From 1982 to 31 December 2002, 44374 of these men died. The mortality hazard ratios (HR) of tobacco-related diseases, including lung cancer, coronary heart disease, stroke and chronic obstructive pulmonary disease, were estimated using Cox proportional hazards regression modelling adjusted for age and other demographic variables, as well as variables associated with smoking history, including number of years smoked, number of cigarettes smoked and age at quitting.

Results: After 20 years of follow-up, switchers had a higher rate of death from any cause (HR 1.08, 95\% confidence interval (Cl) 1.01 to 1.15), lung cancer (HR 1.46, 95\% Cl 1.24 to 1.73), coronary heart disease (HR 1.13, 95\% Cl 1.00 to 1.29) and stroke (HR 1.24, 95\% Cl 1.01 to 1.53) than those who quit using tobacco entirely.

Conclusion: The risks of dying from major tobacco-related diseases were higher among former cigarette smokers who switched to spit tobacco after they stopped smoking than among those who quit using tobacco entirely.
$\mathrm{S}$ everal epidemiological studies have examined morbidity and mortality among users of spit tobacco (spit-tobacco users $),{ }^{12}$ but none have compared the mortality of former cigarette smokers who substitute spit tobacco for cigarette smoking ("switchers") to those of smokers who quit using tobacco entirely. Comprehensive reviews by the US Surgeon General, ${ }^{3}$ and the International Agency for Research on Cancer ${ }^{4}$ and others ${ }^{5}$ have concluded that evidence is sufficient that the use of spit tobacco causes several types of cancer in humans. Although the evidence linking use of spit tobacco to increased risk of cardiovascular diseases is limited, ${ }^{6}$ these products cause acute increases in heart rate and blood pressure, as well as longterm adverse effects on blood pressure and lipid profiles. ${ }^{7}$

We compared mortality of switchers to those of former cigarette smokers who quit using tobacco entirely among men enrolled in a large prospective cohort.

\section{METHODS}

The Cancer Prevention Study II (CPS-II) is an ongoing prospective cohort of 1.2 million US adults (676 306 women and 508351 men) that began in the fall of $1982 .{ }^{89}$ American Cancer Society volunteers asked their friends, neighbours and acquaintances who were at least 30 years old to participate in the study. Each participant completed a confidential, four-page mailed questionnaire on their smoking habits, alcohol intake, education and other characteristics. Members of this cohort are more likely to be college-educated, married, middle-class and white than are members of the general US population. ${ }^{10}$ Informed consent to participate in the study was implied by the return of the self-administered questionnaire. All aspects of the CPS-II study protocol have been reviewed and approved by the Emory University Institutional Review Board, and the protocol is renewed annually.
Since the study began, participants' vital status and (if they died) cause of death have been ascertained biennially by two methods: up to 1988, through personal inquiries from volunteers of the American Cancer Society, with reported deaths verified by death certificate; and since 1988, through automated linkage with the National Death Index. ${ }^{11}$ As of 31 December 2002, 39.4\% of men had died, $60.4 \%$ were still living and $0.2 \%$ had follow-up censored on 1 September 1988, owing to insufficient data for linkage with the National Death Index. Death certificates or multiple causes of death codes were obtained for $98.9 \%$ of all deaths. Participants' person-years at risk were accrued from their month of enrolment through the end of follow-up, the date of their death or the date they were lost to follow-up, whichever occurred first. Age-standardised death rates were directly standardised to the age distribution of person-years among men in CPS-II. ${ }^{12}$

The 1982 questionnaire included questions about current and former use of cigarettes, cigars, pipes, chewing tobacco and snuff. For each form of tobacco, participants were asked about their age when they began using tobacco, the number of years they used, their frequency of use and (for cigarettes, pipes and cigars) their age when they quit. Information on tobacco use was based on their questionnaire responses at enrolment and was not updated during the follow-up. We restricted the cohort to the 116395 men in CPS-II who reported being former exclusive cigarette smokers (ie, who reported having previously used cigarettes but no other tobacco products; $\mathrm{n}=111$ 952) or who reported currently using spit tobacco and having begun doing so at the time of or after they quit exclusive cigarette smoking ("switchers"; $\mathrm{n}=4443$ ). We excluded from the main

Abbreviations: CPS-II, Cancer Prevention Study II; NNK, 4(methylnitrosamino)-1-(3-pyridyl)-1-butanone 
Table 1 Demographic and other characteristics of former cigarette smokers in Cancer Prevention Study-II who quit using tobacco entirely ("quit entirely") or those who substituted spit tobacco for cigarette smoking ("switcher") $)^{*}$

\begin{tabular}{|c|c|c|}
\hline \multirow[b]{2}{*}{ Characteristics } & \multicolumn{2}{|c|}{ Former cigarefte smokers } \\
\hline & Quit entirely & Switcher \\
\hline $\begin{array}{l}n=116395(\%) \\
\text { Median age at enrolment (years) } \\
\text { White (\%) }\end{array}$ & $\begin{array}{l}111952(96) \\
58 \\
96\end{array}$ & $\begin{array}{l}4443(4) \\
56 \\
98\end{array}$ \\
\hline $\begin{array}{l}\text { Educational level (\%) } \\
<\text { High school } \\
\text { High school graduate } \\
\text { Some college } \\
\text { College graduate } \\
\text { Graduate school }\end{array}$ & $\begin{array}{l}13 \\
19 \\
29 \\
20 \\
18\end{array}$ & $\begin{array}{r}30 \\
27 \\
26 \\
9 \\
6\end{array}$ \\
\hline $\begin{array}{l}\text { Current alcohol consumption (\%) } \\
\text { Non-drinker } \\
<1 \text { drink/day } \\
1 \text { drink/day } \\
2-3 \text { drinks/day } \\
\geqslant 4+\text { drinks/day }\end{array}$ & $\begin{array}{r}13 \\
15 \\
8 \\
12 \\
7\end{array}$ & $\begin{array}{r}16 \\
10 \\
5 \\
8 \\
6\end{array}$ \\
\hline $\begin{array}{l}\text { Amount of exercise (\%) } \\
\text { None/slight } \\
\text { Moderate } \\
\text { Heavy }\end{array}$ & $\begin{array}{l}25 \\
64 \\
10\end{array}$ & $\begin{array}{l}16 \\
67 \\
17\end{array}$ \\
\hline $\begin{array}{l}\text { Aspirin use }(\%) \\
\text { Currently employed (\%) } \\
\text { Blue-collar occupation }(\%) \\
\text { Mean body mass index }\left(\mathrm{kg} / \mathrm{m}^{2}\right) \\
\text { Mean weekly vegetable/fruit intake } \\
\text { Mean weekly dietary fat consumption }\end{array}$ & $\begin{array}{l}57 \\
70 \\
23 \\
26.1 \\
18 \\
282\end{array}$ & $\begin{array}{l}57 \\
67 \\
45 \\
26.2 \\
16 \\
310\end{array}$ \\
\hline $\begin{array}{l}\text { Prevalent disease at enrolment (\%) } \\
\text { Cancer } \\
\text { Heart disease or diabetes } \\
\text { Stroke } \\
\text { Chronic bronchitis/emphysema } \\
\text { Any of the above }\end{array}$ & $\begin{array}{r}6 \\
18 \\
2 \\
6 \\
27\end{array}$ & $\begin{array}{r}5 \\
19 \\
2 \\
10 \\
30\end{array}$ \\
\hline
\end{tabular}

analyses men who reported never using any tobacco product ( $22 \%$ of men in CPS-II), currently smoking cigarettes $(25 \%)$, ever smoking pipes or cigars $(20 \%)$, exclusively using spit tobacco $(0.8 \%)$, concurrently smoking and using spit tobacco ( $1.5 \%)$, having uninterpretable or missing data on spit-tobacco use or former cigarette smoking $(5.7 \%)$ or quitting smoking $<2$ years before enrolment $(1.8 \%)$. We also conducted a secondary analysis that included men who reported never having used any tobacco product. We could not include women in our analyses because they were not asked whether they used spit tobacco.

Although updated information on tobacco use was not collected during follow-up on the entire CPS-II cohort, updated smoking information was collected on 184000 people, including 44389 men who reported former smoking in 1982, who participated in the CPS-II Nutrition Cohort, a subset of CPS-II begun in 1992-3. The recruitment and characteristics of the participants of the Nutrition Cohort are described in detail elsewhere. $^{13}$

We examined all-cause mortality and cause-specific mortality for the most common diseases related to cigarette smoking: lung cancer, coronary heart disease, stroke and chronic obstructive pulmonary disease. ${ }^{14}$ For analyses of specific end points, we excluded men who reported having the disease at baseline and for the analysis of all-cause mortality, we excluded men who reported having any of these tobacco-related diseases.

We used Cox proportional hazards models to estimate hazard ratios (HRs) and their 95\% confidence intervals (CIs) to examine the association between mortality and tobacco use while adjusting for other potential risk factors reported at baseline. ${ }^{15}$ We assessed the appropriateness of the Cox proportional hazards model for each cause of death by plotting log $(-\log )$ survival curves against survival time. The log $(\log )$ survival curves were essentially parallel, suggesting that the proportional hazards assumption was met and that the model was appropriate. All statistical tests were two sided; HRs were considered significantly increased if the lower limit of the 95\% CI was >1.0. Indicator variables were used for all independent variables, except for smoking characteristics, which were entered as mean-centred continuous variables. All models were adjusted for single year of age by stratification. We used multivariable Cox proportional hazards models to adjust for race, educational level, current alcohol consumption, level of exercise, aspirin use, body mass index (calculated as weight $(\mathrm{kg}) /\left(\right.$ height $\left.^{2}\right)\left(\mathrm{m}^{2}\right)$ ), quartiles of vegetable and fruit consumption, quartiles of dietary fat consumption and type of occupation. In addition to the above variables, we also controlled for the number of cigarettes formerly smoked per day, the number of years smoked and age at which they quit smoking. Sensitivity analyses to assess the effect of latent illness not reported at baseline excluded men who died within the first 2 years of follow-up.

We also compared mortality of men who never used any tobacco product with those of switchers and smokers who quit using tobacco entirely. As in the main analyses, we excluded men who reported having the disease at baseline, and used Cox proportional hazards models to adjust for covariates. 
Table 3 Mortality hazard (HR) ratios and their 95\% confidence intervals (Cls) comparing men who substituted spit tobacco use for cigarette smoking ("switchers") with men who quit using tobacco use entirely ("quit entirely") Cancer Prevention Study-II, 19822002

\begin{tabular}{|c|c|c|c|c|c|c|}
\hline $\begin{array}{l}\text { Death cause } \\
\text { (ICD-9 codes) }^{*}\end{array}$ & $\begin{array}{l}\text { Tobacco use after } \\
\text { smoking cessation }\end{array}$ & No of death & sDeath rate $†$ & $\begin{array}{l}\text { Age-adjusted HR } \\
(95 \% \mathrm{Cl}) \ddagger\end{array}$ & $\begin{array}{l}\text { Multivariate-adjusted HR } \\
(95 \% \mathrm{Cl}) \S\end{array}$ & $\begin{array}{l}\text { Multivariate-adjusted HR } \\
(95 \% \mathrm{Cl}) \text { बा }\end{array}$ \\
\hline All causes & $\begin{array}{l}\text { Quit entirely } \\
\text { Switcher } \\
\text { Chew only } \\
\text { Snuff only } \\
\text { Chew and snuff }\end{array}$ & $\begin{array}{r}23358 \\
895 \\
620 \\
154 \\
121\end{array}$ & $\begin{array}{l}1685 \\
1994 \\
1944 \\
2112 \\
2114\end{array}$ & $\begin{array}{l}1.00 \text { (referent) } \\
1.19(1.12 \text { to } 1.28) \\
1.17(1.08 \text { to } 1.26) \\
1.25(1.06 \text { to } 1.46) \\
1.27(1.06 \text { to } 1.52)\end{array}$ & $\begin{array}{l}1.00 \text { (referent) } \\
1.13(1.06 \text { to } 1.21) \\
1.12(1.03 \text { to } 1.21) \\
1.15(0.98 \text { to } 1.35) \\
1.17(0.98 \text { to } 1.40)\end{array}$ & $\begin{array}{l}1.00 \text { (referent) } \\
1.08 \text { (1.01 to } 1.15) \\
1.05(0.97 \text { to } 1.14) \\
1.11(0.94 \text { to } 1.30) \\
1.16(0.97 \text { to } 1.39)\end{array}$ \\
\hline Lung cancer (162) & $\begin{array}{l}\text { Quit entirely } \\
\text { Switcher } \\
\text { Chew only } \\
\text { Snuff only } \\
\text { Chew and snuff }\end{array}$ & $\begin{array}{r}2384 \\
155 \\
103 \\
31 \\
21\end{array}$ & $\begin{array}{l}128 \\
233 \\
218 \\
283 \\
248\end{array}$ & $\begin{array}{l}1.00 \text { (referent) } \\
1.92(1.63 \text { to } 2.26) \\
1.79(1.47 \text { to } 2.18) \\
2.28(1.60 \text { to } 3.25) \\
2.19(1.42 \text { to } 3.36)\end{array}$ & $\begin{array}{l}1.00 \text { (referent) } \\
1.76 \text { (1.49 to } 2.07) \\
1.66(1.36 \text { to } 2.02) \\
2.03(1.42 \text { to } 2.91) \\
1.97(1.28 \text { to } 3.03)\end{array}$ & $\begin{array}{l}1.00 \text { (referent) } \\
1.46(1.24 \text { to } 1.73) \\
1.34(1.10 \text { to } 1.64) \\
1.75(1.22 \text { to } 2.50) \\
1.87(1.21 \text { to } 2.87)\end{array}$ \\
\hline $\begin{array}{l}\text { Coronary heart } \\
\text { disease }(410-414)\end{array}$ & $\begin{array}{l}\text { Quit entirely } \\
\text { Switcher } \\
\text { Chew only } \\
\text { Snuff only } \\
\text { Chew and snuff }\end{array}$ & $\begin{array}{r}6075 \\
252 \\
185 \\
41 \\
26\end{array}$ & $\begin{array}{l}386 \\
482 \\
498 \\
492 \\
369\end{array}$ & $\begin{array}{l}1.00 \text { (referent) } \\
1.28(1.13 \text { to } 1.45) \\
1.33(1.15 \text { to } 1.54) \\
1.29(0.95 \text { to } 1.75) \\
1.02(0.70 \text { to } 1.51)\end{array}$ & $\begin{array}{l}1.00 \text { (referent) } \\
1.19(1.04 \text { to } 1.35) \\
1.25(1.08 \text { to } 1.45) \\
1.16(0.85 \text { to } 1.58) \\
0.90(0.61 \text { to } 1.33)\end{array}$ & $\begin{array}{l}1.00 \text { (referent) } \\
1.13(1.00 \text { to } 1.29) \\
1.18(1.02 \text { to } 1.37) \\
1.12(0.82 \text { to } 1.53) \\
0.89(0.60 \text { to } 1.31)\end{array}$ \\
\hline Stroke (430-438) & $\begin{array}{l}\text { Quit entirely } \\
\text { Switcher } \\
\text { Chew only } \\
\text { Snuff only } \\
\text { Chew and snuff }\end{array}$ & $\begin{array}{r}2336 \\
93 \\
66 \\
11 \\
16\end{array}$ & $\begin{array}{l}123 \\
151 \\
151 \\
112 \\
196\end{array}$ & $\begin{array}{l}1.00 \text { (referent) } \\
1.29(1.05 \text { to } 1.59) \\
1.28(1.00 \text { to } 1.63) \\
0.94(0.52 \text { to } 1.69) \\
1.87(1.14 \text { to } 3.05)\end{array}$ & $\begin{array}{l}1.00 \text { (referent) } \\
1.28 \text { (1.04 to } 1.58) \\
1.27(0.99 \text { to } 1.63) \\
0.92(0.51 \text { to } 1.66) \\
1.81(1.11 \text { to } 2.97)\end{array}$ & $\begin{array}{l}1.00 \text { (referent) } \\
1.24(1.01 \text { to } 1.53) \\
1.23(0.96 \text { to } 1.57) \\
0.89(0.49 \text { to } 1.62) \\
1.80 \text { (1.10 to } 2.95)\end{array}$ \\
\hline COPD $(490-492,496)$ & $\begin{array}{l}\text { Quit entirely } \\
\text { Switcher } \\
\text { Chew only } \\
\text { Snuff only } \\
\text { Chew and snuff }\end{array}$ & $\begin{array}{r}878 \\
44 \\
32 \\
9 \\
3\end{array}$ & $\begin{array}{l}49 \\
84 \\
86 \\
92 \\
63\end{array}$ & $\begin{array}{l}1.00 \text { (referent) } \\
1.74(1.29 \text { to } 2.36) \\
1.75(1.23 \text { to } 2.50) \\
2.19(1.14 \text { to } 4.23) \\
1.03(0.33 \text { to } 3.19)\end{array}$ & $\begin{array}{l}1.00 \text { (referent) } \\
1.53 \text { (1.13 to } 2.08) \\
1.53 \text { (1.07 to } 2.18) \\
1.94 \text { (1.00 to } 3.75) \\
0.89 \text { (0.29 to } 2.78)\end{array}$ & $\begin{array}{l}1.00 \text { (referent) } \\
1.31 \text { (0.96 to } 1.78) \\
1.26(0.88 \text { to } 1.80) \\
1.68(0.87 \text { to } 3.26) \\
0.91 \text { (0.29 to } 2.84)\end{array}$ \\
\hline
\end{tabular}

COPD, chronic obstructive pulmonary disease; ICD-9, International Classification of Diseases-ninth edition.

*Analysis for all causes excluded men who reported a history of cancer, heart disease, diabetes, stroke, chronic bronchitis or emphysema in 1982 (28\%); analysis for lung cancer excluded men who reported a history of any cancer except non-melanoma skin cancer in 1982 (6\%); analysis for coronary heart disease excluded men who reported a history of heart disease or diabetes in 1982 (19\%); analysis for stroke excluded men who reported a history of stroke in 1982 (2\%); analysis for COPD excluded men who reported a history of chronic bronchitis or emphysema in 1982 (6\%). "Chew and snuff" includes men who currently use both chewing tobacco and snuff, and men who currently use only one product and reported past use of the other product.

†Death rates are per 100000 person-years and are age-standardised to the Cancer Prevention Study-ll male person-year distribution.

tFrom Cox proportional hazards models, adjusted for age only.

§From Cox proportional hazards models adjusted for age, race, educational level, body mass index, exercise level, alcohol consumption, employment type, employment status, fat consumption, fruit and vegetable intake and aspirin use.

-From Cox proportional hazards models adjusted for age, number of cigarettes formerly smoked per day, number of years smoked cigarettes, age at which they quit smoking cigarettes, race, educational level, body mass index, exercise level, alcohol consumption, employment type, employment status, fat consumption, fruit and vegetable intake and aspirin use.

follow-up did not materially change the results (data not shown).

Figure 1 illustrates the HRs and associated 95\% CIs comparing tobacco-attributable mortality of switchers and former cigarette smokers who quit using tobacco entirely with those of men who never used any tobacco product. Switchers experienced a significantly higher risk of dying from lung cancer, coronary heart disease and stroke than both never tobacco users and those who quit using tobacco entirely.

\section{DISCUSSION}

This is the first known prospective cohort study to compare mortality among former cigarette smokers who substituted spit tobacco for cigarette smoking with those who quit using tobacco entirely. Our principal finding was that switchers had significant higher rates of death from lung cancer statistically, coronary heart disease and stroke than men who quit using tobacco entirely.

A key question is whether the increased risk is causally associated with use of spit tobacco or whether it reflects residual confounding by factors such as the lower socioeconomic status of men who use these products. ${ }^{16}$ Although we controlled for type of employment and educational level, we could not resolve this question conclusively because of possible residual confounding that could account for some or all of the increased risk. It does suggest, however, that substituting spit-tobacco products available in the US market at the time of study follow-up for cigarette smoking instead of quitting all forms of tobacco use may have adverse consequences beyond the established relationships between the use of spit tobacco and risk of oral and pancreatic cancer. ${ }^{45}$ Few studies have examined lung cancer in association with exclusive use of spit tobacco and results are inconsistent. ${ }^{217-19}$ In case-control analyses nested within the first National Health and Nutrition Examination Study, an increased risk was observed in women (mortality HR 9.1, 95\% CI 1.1 to $75.4^{17}$; incidence HR $6.8,95 \%$ CI 1.6 to $28.5^{18}$ ) but not in men. In a previous analysis of our cohort, an increased risk was seen in CPS-II (HR 2.00, 95\% CI 1.23 to 3.24), but not in CPS-I (HR $1.08,95 \%$ CI 0.64 to 1.83). ${ }^{2}$ A causal relationship between the use of spit tobacco and lung cancer risk is biologically plausible given the high nitrosamine content of these products. In 2000, the total nitrosamine content of select US brands of snuff ranged from 4.6 to $37.6 \mu \mathrm{g} / \mathrm{g}$ of tobacco. ${ }^{20}$ In 1986, the US Surgeon General determined that the daily level of carcinogenic tobacco-specific nitrosamines ingested by the average US spit-tobacco user was $>100$ times the permissible level of nitrosamines in any commercial product regulated by the Food and Drug 

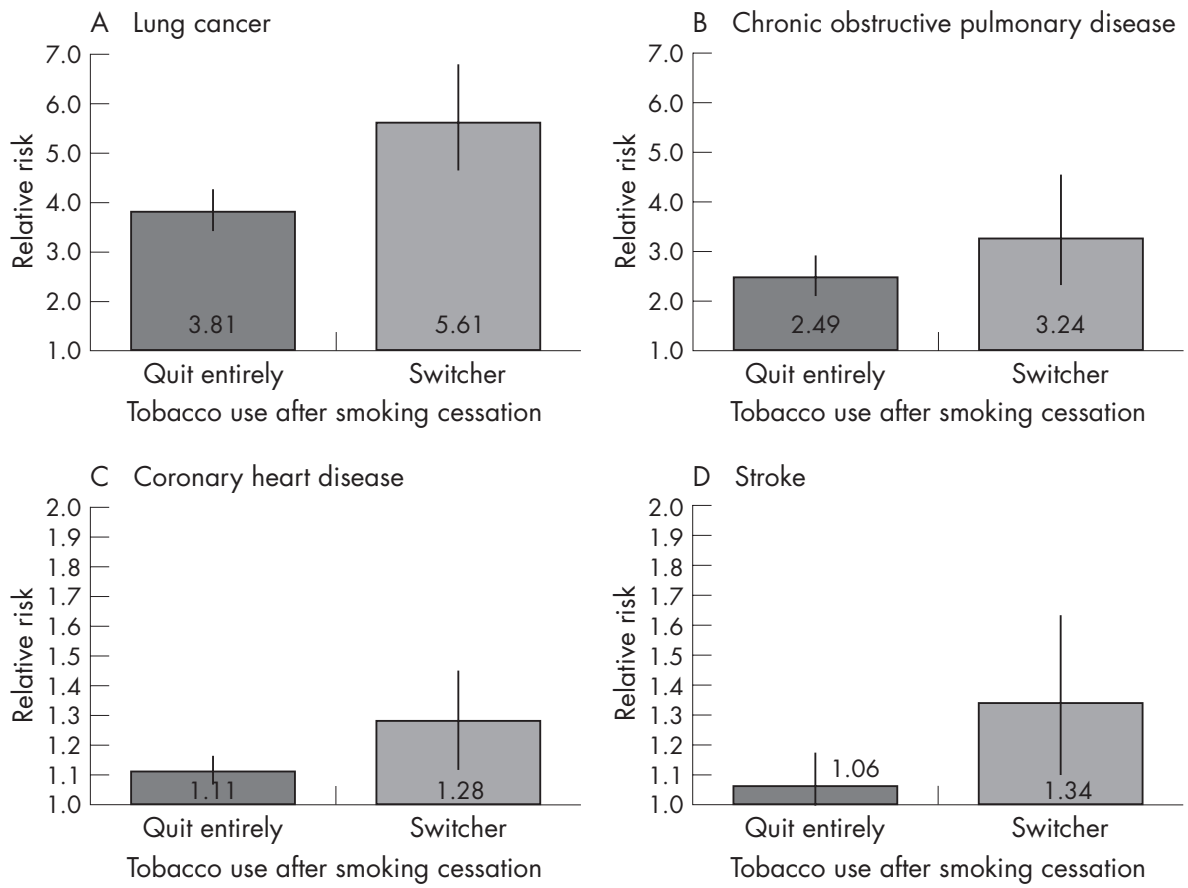

Figure 1 Relative risk estimates for tobacco-attributable diseases for former cigarette smokers who quit using tobacco entirely ("quit entirely") and former cigarette smokers who substituted spit tobacco for cigarette smoking ("switcher") compared with men who never used any tobacco products, Cancer Prevention Study II (CPS-II), 1982-2002 (excluding men who reported having the disease when they entered the study). Grey and dark grey bars represent the magnitude of the relative risk estimates (actual values are given inside the bar), and the vertical lines through the centre of each bar represent the $95 \% \mathrm{Cls}$ around the estimate of relative risk. Estimates were calculated using Cox proportional hazards regression modelling and are adjusted for age, race, educational level, body mass index, exercise level, alcohol consumption, employment type, employment status, fat consumption, fruit and vegetable intake, aspirin use, the number of cigarettes formerly smoked per day, the number of years smoked cigarettes and age at which they quit smoking cigarettes.

Administration or the US Department of Agriculture. ${ }^{3}$ Large amounts of tobacco-specific nitrosamines, particularly the carcinogenic 4-(methylnitrosamino)-1-(3-pyridyl)-1-butanone (NNK), are formed during the ageing, curing, and fermentation processes of tobacco used to manufacture chewing tobacco and snuff. ${ }^{21}$ In rodents, NNK was shown to be a strong, systemic lung carcinogen that induces lung tumours independent of its route of administration..$^{22}$ Adequate data on humans are not available to evaluate the carcinogenicity of NNK, but on the basis of sufficient evidence of carcinogenicity in experimental animals, NNK is reasonably expected to be a human carcinogen. ${ }^{23}$

It is also biologically plausible that spit tobacco could increase cardiovascular risk, given that these products have been shown to have acute adverse effects on heart rate and blood pressure, and long-term adverse effects on blood pressure and lipid profiles. ${ }^{7}$ Although studies on the incidence of coronary heart disease and stroke have not observed increased risk among men who use spit tobacco, ${ }^{24-28}$ studies on mortality due to cardiovascular disease have observed higher risk among spit-tobacco users, ${ }^{217} 192527$ albeit not always significantly higher in smaller studies. ${ }^{17} 2527$ Spit tobacco contains numerous chemicals such as nicotine, sodium and liquorice that are known to affect cardiovascular function adversely. ${ }^{3}$

Two important strengths of our study are its large sample size and prospective design, which allowed us to examine multiple end points among groups with different patterns of tobacco use. Another strength was the 20-year follow-up period, which allowed us to produce moderately stable HR estimates. (The absolute rates represent the average annual death rate over the 20-year period.)

A major limitation of our study is that because information on tobacco use was collected only at baseline and not updated during follow-up, men who quit smoking before enrolment, but resumed during the follow-up period, and those who initiated or discontinued using spit tobacco after enrolment would have been misclassified. In a subset of our cohort whose smoking status was updated after 10 years, the overall rate of recidivism after 10 years was low, but significantly higher among switchers $(3.0 \%)$ than among those who quit using tobacco entirely $(1.4 \%)$. The relapse rate would continue to decrease with time since cessation and would be lower during the second than in the first 10 years of follow-up. This level of misclassification would not affect our estimates substantially. For example, if we assume that the observed death rate among men we classified as former smokers is the average of the "true" death rate among men who remained abstinent and the death rate among those who resumed smoking (approximated by the death rate among current smokers), weighted by the proportion of men in each category, then the "true" ratio of the all-cause death rates between switchers and men who quit using tobacco entirely would be 1.07 rather than the 1.08 we observed. Although we do not have updated information on smoking for the entire CPS-II cohort, the rate of smoking relapse we observed in the Nutrition Cohort is comparable with that from other studies. For example, the California Tobacco Survey found that the likelihood of remaining abstinent was 95\% after 1 year and 97\% after 3 years. ${ }^{29}$ Similarly, the VA Normative Aging Study ${ }^{30}$ reported that the rate of smoking relapse was $<1 \%$ after 10 years of abstinence.

A related concern is the extent to which addiction may have influenced both smoking behaviour and use of spit tobacco. Former smokers who switch to spit tobacco are, on average, possibly more addicted to nicotine than those who stop all forms of tobacco use, or they may have smoked differently. ${ }^{31}$ 


\section{What is already known on this subject}

- The use of snuff and chewing tobacco causes several types of cancer in humans, and some cohort studies suggest that the use of spit tobacco is associated with increased risk of cardiovascular disease; however, no studies have compared the mortality of former cigarette smokers who substitute spit tobacco for cigarette smoking ("switchers") to those of smokers who quit tobacco use entirely.

\section{What this study adds}

- Our study suggests that switching from smoking to using spit tobacco compares unfavourably with both complete tobacco cessation and complete abstinence from all tobacco products and supports the stand that smokers who want to quit should be offered safe, clinically proved treatments for smoking cessation.

Although we controlled for the number of cigarettes smoked per day before cessation and for the number of years smoked, we could not control for subtle variations such as the intensity with which cigarettes were smoked.

Our findings supplement other data from this cohort showing that men who exclusively used spit tobacco had higher death rates for lung cancer (HR 2.0), coronary heart disease (HR 1.3), stroke (HR 1.4) and all causes combined (HR 1.2) than those who had never used any tobacco product. ${ }^{2}$ Together, our studies suggest that using spit tobacco compares unfavourably with both complete tobacco cessation and complete abstinence from all tobacco products.

In summary, we found that men who switched from smoking cigarettes to using spit tobacco had a higher rate of death from all causes, lung cancer, coronary heart disease and stroke than those who had never used tobacco or those who were former cigarette smokers and quit using tobacco entirely. Our results support the stand that smokers who want to quit should be offered safe, clinically proved treatments for smoking cessation, including pharmacotherapies such as medicinal nicotine or antidepressants, behavioural counselling and telephone quit lines. ${ }^{32-34}$

\section{ACKNOWLEDGEMENTS}

We thank Scott Tomar for providing helpful comments on the study design, the 1.2 million American men and women who have participated in the Cancer Prevention Study II, the volunteers of the American Cancer Society and the CPS-II Study Management Group for their assistance in developing these cohorts.

\section{Authors' affiliations}

S J Henley, C J Connell, E E Calle, M J Thun, Epidemiology and Surveillance Research, American Cancer Society, Atlanta, Georgia, USA P Richter, C Husten, T Pechacek, Office of Smoking and Health, National Center for Chronic Disease Prevention and Health Promotion, Centers for Disease Control and Prevention, Atlanta, Georgia, USA

Funding: The Cancer Prevention Study II cohort is supported by the American Cancer Society. This publication was supported in part by Grant/Cooperative Agreement Number U50/CCU424071-02 from the Centers for Disease Control and Prevention. Its contents are solely the responsibility of the authors and do not necessarily represent the official views of Centers for Disease Control and Prevention.

Competing interests: None declared.
Contributors: Staff of the Epidemiology and Surveillance Research Department of the American Cancer Society designed and conducted the study, including collection, analysis, interpretation and presentation of the manuscript; no staff at the American Cancer Society, other than study investigators, reviewed or approved the manuscript. Staff at the Office of Smoking and Health at the Centers for Disease Control and Prevention contributed to the study design, interpretation and presentation; the Centers for Disease Control and Prevention reviewed and approved this manuscript before submission.

\section{REFERENCES}

1 Critchley JA, Unal B. Health effects associated with smokeless tobacco: a systematic review. Thorax 2003;58:435-43.

2 Henley SJ, Thun MJ, Connell C, et al. Two large prospective studies of mortality among men who use snuff or chewing tobacco (United States). Cancer Causes Control 2005; 16:347-58.

3 US Department of Health and Human Services. The health consequences of using smokeless tobacco: a report of the Advisory Committee to the Surgeon General. Atlanta, GA: US Department of Health and Human Services, National Institutes of Health, National Cancer Institute, 1986.

4 International Agency for Reserach on Cancer. Tobacco habits other than smoking; betel-quid and areca nut chewing; and some related nitrosamines, Vol 37. Lyon, France: International Agency for Research on Cancer, 1985

5 Cogliano V, Straif K, Baan R, et al. Smokeless tobacco and tobacco-related nitrosamines. Lancet Oncol 2004;5:708.

6 Critchley JA, Unal B. Is smokeless tobacco a risk factor for coronary heart disease? A systematic review of epidemiological studies. Eur J Cardiovasc Prev Rehabil 2004;11:101-12.

7 Gupta R, Gurm H, Bartholomew JR. Smokeless tobacco and cardiovascular risk. Arch Intern Med 2004; 164:1845-9.

8 Garfinkel L. Selection, follow-up and analysis in the American Cancer Society prospective studies. Monogr Natl Cancer Inst 1985;67:49-52.

9 Stellman SD, Garfinkel L. Smoking habits and tar levels in a new American Cancer Society prospective study of 1.2 million men and women. J Natl Cancer Inst 1986;76:1057-63.

10 Thun M, Calle E, Rodriguez C, et al. Epidemiological research at the American Cancer Society. Cancer Epidemiol Biomarkers Prev 2000;9:861-8

11 Calle E, Terrell D. Utility of the National Death Index for ascertainment of mortality among Cancer Prevention Study II particpants. Am J Epidemiol 1993;137:235-41.

12 Breslow N, Day N. Statistical methods in cancer research: the design and analysis of cohort studies, Vol 2. Lyon, France: International Agency for Research on Cancer, 1987

13 Calle EE, Rodriguez C, Jacobs EJ, et al. The American Cancer Society Cancer Prevention Study II Nutrition Cohort: rationale, study design, and baseline characteristics. Cancer 2002;94:500-11.

14 US Department of Health and Human Services. The health consequences of smoking: a report of the Surgeon General. Atlanta, GA: US Department of Health and Human Services, Centers for Disease Control and Prevention National Center for Chronic Disease Prevention and Health Promotion, Office on Smoking and Health, 2004.

15 Cox D. Regression models and life tables. J R Stat Soc 1972;34:187-220.

16 Centers for Disease Control. Use of smokeless tobacco among adults-United States, 1991. MMWR Morb Mortal Wkly Rep, 1993;42:263-6.

17 Accortt NA, Waterbor JW, Beall C, et al. Chronic disease mortality in a cohort of smokeless tobacco users. Am J Epidemiol 2002;156:730-7.

18 Accortt NA, Waterbor JW, Beall C, et al. Cancer incidence among a cohort of smokeless tobacco users (United States). Cancer Causes Control 2005; 16:1107-15

19 Bolinder G, Alfredsson L, Englund A, et al. Smokeless tobacco use and increased cardiovascular mortality among Swedish construction workers. Am J Public Health 1994:84:399-404.

20 Brunnemann KD, Qi J, Hoffmann D. Chemical profile of two types of oral snuff tobacco. Food Chem Toxicol 2002;40:1699-703.

21 Hecht SS. Tobacco carcinogens, their biomarkers and tobacco-induced cancer. Nat Rev Cancer 2003;3:733-44.

22 Hecht SS. Biochemistry, biology, and carcinogenicity of tobacco-specific $\mathrm{N}$ nitrosamines. Chem Res Toxicol 1998;11:559-603.

23 US Department of Health and Human Services. Report on carcinogens, 11 th edn. Atlanta: US Department of Health and Human Services, Public Health Service, National Toxicology Program, 2005, http://ntp.niehs.nih.gov/ntp/roc/ toc $11 . \mathrm{html}$.

24 Huhtasaari F, Asplund K, Lundberg V, et al. Tobacco and myocardia infarction: is snuff less dangerous than cigarettes? BMJ 1992;305 1252-6

25 Huhtasaari F, Lundberg V, Eliasson M, et al. Smokeless tobacco as a possible risk factor for myocardial infarction: a population-based study in middle-aged men. J Am Coll Cardiol 1999:34:1784-90.

26 Asplund K, Nasic S, Janlert U, et al. Smokeless tobacco as a possible risk factor for stroke in men: a nested case-control study. Stroke 2003;34:1754-9.

27 Hergens MP, Ahlbom A, Andersson T, et al. Swedish moist snuff and myocardia infarction among men. Epidemiology 2005; 16:12-16. 
28 Johansson SE, Sundquist K, Qvist J, et al Smokeless tobacco and coronary heart disease: a 12-year follow-up study. Eur J Cardiovasc Prev Rehabil 2005; 12:387-92.

29 Gilpin EA, Pierce JP, Farkas AJ. Duration of smoking abstinence and success in quitting. J Natl Cancer Inst 1997;89:572-6.

30 Krall EA Garvey AJ, Garcia RI. Smoking relapse after 2 years of abstinence: findings from the VA Normative Aging Study. Nicotine Tob Res 2002;4:95-100.

31 Tomar S. Snuff use and smoking in U.S. men: implications for harm reduction, Am J Prev Med 2002;23:143-9.
32 Fiore $\mathrm{M}$, Bailey $\mathrm{W}$, Cohen $\mathrm{S}$, et al Treating tobacco use and dependence. Rockville, MD: US Department of Health and Human Services, Public Health Service, 2000.

33 Fiore MC, Croyle RT, Curry SJ, et al. Preventing 3 million premature deaths and helping 5 million smokers quit: a national action plan for tobacco cessation. Am J Public Health 2004;94:205-10.

34 Henningfield JE, Fant RV, Buchhalter AR, et al. Pharmacotherapy for nicotine dependence. CA Cancer J Clin 2005;55:281-99.

\section{Clinical Evidence-Call for contributors}

Clinical Evidence is a regularly updated evidence-based journal available worldwide both as a paper version and on the internet. Clinical Evidence needs to recruit a number of new contributors. Contributors are healthcare professionals or epidemiologists with experience in evidence-based medicine and the ability to write in a concise and structured way.

Areas for which we are currently seeking contributors:

- Pregnancy and childbirth

- Endocrine disorders

- Palliative care

- Tropical diseases

We are also looking for contributors for existing topics. For full details on what these topics are please visit www. clinicalevidence.com/ceweb/contribute/index.jsp

However, we are always looking for others, so do not let this list discourage you.

Being a contributor involves:

- Selecting from a validated, screened search (performed by in-house Information Specialists) epidemiologically sound studies for inclusion.

- Documenting your decisions about which studies to include on an inclusion and exclusion form, which we keep on file.

- Writing the text to a highly structured template (about 1500-3000 words), using evidence from the final studies chosen, within 8-10 weeks of receiving the literature search.

- Working with Clinical Evidence editors to ensure that the final text meets epidemiological and style standards.

- Updating the text every 12 months using any new, sound evidence that becomes available. The Clinical Evidence in-house team will conduct the searches for contributors; your task is simply to filter out high quality studies and incorporate them in the existing text.

If you would like to become a contributor for Clinical Evidence or require more information about what this involves please send your contact details and a copy of your CV, clearly stating the clinical area you are interested in, to CECommissioning@bmigroup.com.

\section{Call for peer reviewers}

Clinical Evidence also needs to recruit a number of new peer reviewers specifically with an interest in the clinical areas stated above, and also others related to general practice. Peer reviewers are healthcare professionals or epidemiologists with experience in evidence-based medicine. As a peer reviewer you would be asked for your views on the clinical relevance, validity, and accessibility of specific topics within the journal, and their usefulness to the intended audience (international generalists and healthcare professionals, possibly with limited statistical knowledge). Topics are usually 1500-3000 words in length and we would ask you to review between 2-5 topics per year. The peer review process takes place throughout the year, and out turnaround time for each review is ideally 10-14 days.

If you are interested in becoming a peer reviewer for Clinical Evidence, please complete the peer review questionnaire at www.clinicalevidence.com/ceweb/contribute/peerreviewer.jsp 